\title{
O risco fiscal associado às parcerias público-privadas (PPP): estudo de caso da rodovia MG-050
}

Danielle Carvalho Ribeiro

Bacharela em Administração Pública pela Escola de Governo da Fundação João Pinheiro , com período sanduíche na Faculdade de Economia da Université Picardie Jules Vernes, Mestranda em Administração, com ênfase em Finanças, pela Universidade Federal de Minas Gerais. Servidora Pública no Governo do Estado de Minas Gerais, Minas Gerais, Brasil

$$
\text { a.daniellecarvalho@gmail.com }
$$

Aureliano Angel Bressan

Professor de Finanças no Departamento de Ciências Administrativas (CAD) da Universidade Federal de Minas Gerais (UFMG) e do Centro de Pós-Graduação e Pesquisas em

Administração - CEPEAD/UFMG. Graduado em Economia pela UFRJ e doutorado em Economia Aplicada pela UFV, Minas Gerais, Brasil

bressan@face.ufmg.br

Robert Aldo lquiapaza

Professor de Finanças no Departamento de Ciências Administrativas (CAD) da Universidade Federal de Minas Gerais (UFMG) e membro permanente do Centro de Pós-Graduação e Pesquisas em Administração - CEPEAD/UFMG. Graduado em Economia pela Universidad Nacional de San Agustín - UNSA/Arequipa/Peru, mestrado e doutorado em Administração (Finanças) pelo Centro de Pós-Graduação e Pesquisas em Administração. Pesquisador do NUFI/FACE/UFMG, Minas Gerais, Brasil.

rbali@ufmg.br

\begin{tabular}{|c|} 
Editor Científico: José Edson Lara \\
Organização Comitê Científico \\
Double Blind Review pelo SEER/OJS \\
Recebido em 08.01.2016 \\
Aprovado em 23.02.2017
\end{tabular}

Este trabalho foi licenciado com uma Licença Creative Commons - Atribuição - Não Comercial 3.0 Brasil 


\title{
Resumo
}

Esse trabalho tem como objetivo analisar, a partir do estudo de caso da Parceria Público-Privada (PPP) Rodovia MG-050, o risco fiscal assumido pelo Poder Público na execução de Parcerias Público-Privadas. No caso da MG-050, elege-se o risco de variação do volume de tráfego na rodovia como variável-chave para a análise do potencial impacto da execução desse projeto sobre as contas públicas, denominado risco fiscal. Utilizam-se os registros históricos do volume de tráfego na rodovia no período de 2008 a 2015 para alimentar o processo de reamostragem, a partir do método estatístico bootstrap, de modo a permitir a verificação da tendência de oscilação do volume de tráfego em relação àquele projetado. Constata-se que a tendência de variação é pequena, não implicando em ônus financeiros para o Poder Público. Conclui-se, portanto, que a projeção do volume de tráfego rodoviário para PPP Rodovia MG-050 parece ter sido realizada de modo adequado, mitigando possíveis riscos fiscais associados a esse contrato.

Palavras-chave: Parceria Público-Privada (PPP); MG-050; Risco Fiscal; Bootstrap.

\section{The fiscal risk associated to public private-partnerships (PPP): MG-050 Highway study case}

\begin{abstract}
This study aims to analyze, from the case study of the Public-Private Partnership (PPP) Highway MG-050, the fiscal risk taken by the Government in the implementation of Public-Private Partnerships. In the case of MG-050, we elect the risk of variation in the traffic volume on the highway as the key variable to analyze the potential impact of the implementation of this Partnership on public accounts, which we call here the fiscal risk. We use the historical records of the traffic volume on the highway from 2008 to 2015 to feed the resampling process, via the statistical method bootstrap, in order to allow us check the oscillating trend of the traffic volume compared to the one expected. It appears that the variation trend is small, not imposing financial burden on the Government. We conclude, therefore, that the projection of road traffic volume for PPP highway MG-050 seems to be adequate, mitigating potential fiscal risks associated with this contract.
\end{abstract}

Keywords: Public-Private Partnerships (PPP); MG-050; Fiscal Risk; Bootstrap. 


\section{El riesgo fiscal asociado a las asociaciones público-privadas (APP): estudio de caso de la autopista MG-050}

\section{Resumen}

El objetivo fue analizar, a partir del estudio de caso de la Asociacione PúblicoPrivadas (APP) autopista MG-050, el riesgo fiscal asumido por el Gobierno en la ejecución de Asociaciones Público-Privadas. En el caso de la MG-050, se seleccionó el riesgo de variación del volumen de tráfico en la autopista como una variable clave para el análisis del potencial efecto de la ejecución de este proyecto en las cuentas públicas, denominado riesgo fiscal. Se utilizó registros históricos del volumen de tráfico en la autopista de 2008 a 2015 para alimentar el proceso de remuestreo, utilizando la técnica estadística de bootstrap, con el fin de permitir la verificación de la tendencia de fluctuación del volumen de tráfico en relación con el proyectado. Se observó que la tendencia de variación es pequeña, no imponiendo carga financiera para el Gobierno. De ello se desprende, por lo tanto, que la proyección del volumen de tráfico terrestre para la APP autopista MG-050 parece haber sido llevada a cabo adecuadamente, mitigando los posibles riesgos fiscales asociados a este contrato.

Palabras clave: APP; MG-050; Riesgo fiscal; Bootstrap.

\section{Introdução}

A Parceria Público-Privada (PPP) apresenta-se como mecanismo alternativo para a inserção da iniciativa privada na consecução de investimentos em infraestrutura e melhoria da provisão de serviços públicos. Uma década após a instituição da Lei Federal 11.079 de 30 de dezembro de 2004, que define normas gerais para licitação e contratação de projetos de PPP no âmbito da administração pública, esses projetos têm se apresentado como mecanismos eficazes para a realização de investimentos em infraestrutura relacionada à prestação de serviços públicos, permeando as mais diversas áreas econômicas, seja mobilidade urbana, saneamento básico, saúde ou, até mesmo, segurança pública. Há fortes indicativos de que a PPP continuará a ser adotada como ferramenta para a realização de investimentos públicos no Brasil como, por exemplo, a grande quantidade de projetos em processo de elaboração (Loiola, 2013).

A principal justificativa para a adoção da PPP em território nacional é a necessidade do setor público de atender a constantes demandas por investimentos diante de um contexto de recursos limitados. Além disso, a literatura aponta, entre os fatores que propiciam a disseminação da PPP, a possibilidade de se obter, a partir 
do uso desse instrumento, ganhos de eficiência na prestação do serviço público, atração de capital de risco e redução de incertezas com soluções de longo prazo (Thamer \& Lazzarini, 2015).

Desse modo, para que não haja desvirtuamento do uso da PPP e para que os potenciais benefícios proporcionados por esse mecanismo à gestão pública não sejam perdidos, é de suma importância o acompanhamento e o controle, pelos órgãos competentes, dos contratos executados pelos órgãos públicos. De modo especial, para a mitigação do risco fiscal, entendido como o risco de impacto negativo nas contas públicas, para além das despesas contratuais já previstas e programadas, em função dos compromissos assumidos pelo setor público nos contratos de PPP, deve-se atentar para a possibilidade de contabilização dos contratos de PPP fora do balanço da administração pública (off government balance sheet). Esse tipo de contabilização permite que os investimentos realizados nos contratos de PPP não sejam computados no cálculo do déficit e da dívida pública durante a fase de implementação dos mesmos, contabilizando no balanço público somente os pagamentos do Poder Público ao parceiro privado, os quais são diluídos durante todo o prazo de execução do contrato (Sarmento \& Renneboog, 2014).

No que se refere ao controle legal do risco fiscal associado à PPP, é definido no art. 28 da Lei Federal 11.079/2004 que as despesas de caráter continuado derivadas dos contratos de PPP firmados pelos entes federados não podem superar - limite de $5 \%$ da sua Receita Corrente Líquida anual. A legislação prevê a possibilidade de aplicação de sanções pelo Governo Federal para os Estados ou Municípios que não respeitarem essa regra. Contudo, para garantir o cumprimento da Lei, bem como a gestão eficiente do orçamento, faz-se fundamental acompanhar a evolução das despesas de cada contrato de PPP vigente, analisando, além das despesas já programadas, os passivos contingentes dos contratos que possam vir a alterar as contas públicas.

Os passivos contingentes podem ser entendidos como elementos cujos fatos geradores já se materializaram, porém, cujos efeitos sobre o patrimônio são incertos e ainda não se confirmaram (Campos, 2015). O Fundo Monetário Internacional (FMI), por sua vez, conceitua passivos contingentes como passivos eventuais, os quais consistiriam em compromissos reais assumidos, cujas consequências fiscais 
definitivas dependem de fatos futuros cuja ocorrência é incerta (Fundo Monetário Internacional, 2007).

Apesar de haver ainda muitas discussões acerca da forma mais adequada de contabilização das PPPs sob a perspectiva de responsabilidade fiscal dos entes públicos, a Portaria da Secretaria do Tesouro Nacional n.614/2006 estabelece que, nos casos em que o Poder Público assumir parte relevante dos riscos de demanda, disponibilidade ou construção em um contrato de PPP, esses deverão ser contabilizados como dívida pública em seu balanço, tamanho é o impacto potencial sobre as finanças públicas decorrente de fenômenos dessas naturezas (Guimarães, 2010). Assim, embora existam múltiplos elementos que possam impactar no valor de cada contrato, é possível delimitar quais são as variáveis-chave que ocasionam as maiores variações, a fim de manter o foco no acompanhamento das mesmas, tornando assim mais estratégica a gestão do risco fiscal.

Em cada contrato, as variáveis-chave a serem acompanhadas podem ser delimitadas pela análise das fórmulas de cálculo para a composição da remuneração do parceiro privado e dos riscos assegurados total ou parcialmente pelo Poder Público. O passo subsequente à definição das variáveis-chave é a realização de simulações com base em dados históricos observados para tais variáveis, projetando diferentes valores para as variáveis-chave de cada contrato e os impactos financeiros no valor contratual correspondente a cada um deles, a fim de quantificar os impactos fiscais em cada cenário possível. Assim, a presente pesquisa propõe a investigação do risco fiscal associado aos contratos de PPP a partir do estudo de caso da PPP Rodovia MG-050.

Dado o exposto, propõe-se o seguinte problema de pesquisa: "Quais os possíveis impactos financeiros decorrentes dos compromissos assumidos pelo Estado de Minas Gerais no contrato da PPP Rodovia MG-050?"

O principal objetivo desse estudo é simular os potenciais impactos financeiros associados aos compromissos assumidos pelo Estado de Minas Gerais no contrato da PPP Rodovia MG-050. Como objetivos específicos, propõe-se:

- Verificar os dados históricos do volume de tráfego efetivamente observados do início da PPP até junho de 2015 e compará-los à projeção de tráfego elaborada Departamento de Estradas de Rodagem de Minas Gerais (DER/MG) para o período; 
- A partir dos dados históricos, simular outros cenários para o volume de tráfego no mesmo período, a fim de verificar como se comportam tais simulações em relação aos dados projetados;

- Justificar a importância do acompanhamento dos riscos fiscais associados aos contratos de PPP.

\section{Referencial Teórico}

\subsection{O risco fiscal associado às Parcerias Público-Privadas}

Diante do contexto de recursos limitados para o atendimento de uma vasta quantidade de demandas sociais, faz-se importante impor aos órgãos públicos regras que induzam um maior esforço dos agentes no exercício de uma gestão orçamentária de qualidade (Campos, 2015).

A Lei Complementar 101 de 04 de Maio de 2000, a Lei de Responsabilidade Fiscal (LRF), estabelece diversas normas e diretrizes para os órgãos públicos, regras de gerenciamento de despesas a regras de controle do estoque da dívida, com o objetivo de assegurar, assim, o equilíbrio das contas públicas (Guimarães, 2010). Muitas vezes, fatores macroeconômicos impõem incertezas sobre a arrecadação e sobre os compromissos com dívidas, exigindo o acompanhamento e realização de revisões constantes no orçamento para garantir o alcance das metas fiscais estabelecidas (Cunha, 2005).

Ao possibilitar o compartilhamento de riscos entre as partes contratuais, de modo que cada risco possa ser alocado àquele que pode melhor controla-lo, a PPP faz com que esses contratos apresentem, de modo geral, performances mais eficientes que contratos públicos tradicionais (Archanjo, 2006). O gerenciamento dos riscos assumidos requer a adoção de ações que reduzam a probabilidade de ocorrência do fenômeno gerador do risco ou, caso ele ocorra, seu impacto sobre o projeto e sobre os agentes envolvidos (Franco, 2007). Mais especificamente, sob a perspectiva das finanças públicas, a gestão de riscos consiste na identificação, 
classificação e quantificação dos elementos capazes de impactar o orçamento público (Rodrigues \& Lopes, 2006).

Contudo, ao mesmo tempo em que o compartilhamento objetivo de riscos entre as partes pode ser sinônimo de maior eficiência, os riscos assumidos pelo poder público podem representar riscos fiscais para as contas públicas. Por isso, é importante avaliar a probabilidade de ocorrência de cada risco assumido e os potenciais impactos deles, caso ocorram (Campos, 2015).

$\mathrm{O}$ art. 4 da Lei Federal de PPPs define que as Parcerias Público-Privadas deverão observar, entre outras diretrizes, a de responsabilidade fiscal na celebração e execução das parcerias (Lei n.11079, 2004). Antes da promulgação da LRF, não havia no setor público noção da importância do acompanhamento contínuo e sistemático dos passivos contingentes e riscos fiscais de outra natureza e seus impactos nas contas públicas (Rodrigues \& Lopes, 2006). De acordo com os mesmos autores, com o advento dessa Lei, passou a ser compulsória, para a União, estados e municípios brasileiros, a elaboração do demonstrativo denominado Anexo de Riscos Fiscais, que integra a Lei de Diretrizes Orçamentárias e elenca os riscos fiscais potencialmente capazes de impactar as finanças públicas, conforme disposto no $\S 3^{\circ}$ do art. $4^{\circ}$ da LRF.

O conceito de risco fiscal a ser considerado nesse estudo compreende o risco de impacto negativo no orçamento público, para além das despesas contratuais já previstas e programadas, dados os compromissos assumidos pelo setor público nos contratos de PPP. O risco fiscal pode ser mitigado, entre outras formas, a partir da compreensão da imprescindibilidade da responsabilidade fiscal em todas as ações do Poder Público. Conforme Guimarães (2010):

No universo das PPPs, a responsabilidade fiscal é um aspecto de enorme relevância. Estes contratos, de longuíssima duração e de acentuada dimensão econômico-financeira, envolvem em todos os casos o comprometimento de recursos públicos (e, na grande maioria dos casos, o comprometimento de contraprestações pecuniárias providas pelo parceiro público), além da possibilidade da distribuição de riscos (imprevisíveis, inclusive) entre o parceiro público e o parceiro privado, com efeitos hábeis a impactar orçamentos futuros. Estas características atraem as cautelas da responsabilidade fiscal, submetendo os ajustes de PPP ao atendimento daquela Lei, inclusive aos sistemas de controle de fluxo e de controle de estoque da dívida, nos termos adiante examinados (Guimarães, 2010, p.1). 


\subsection{PPP Rodovia MG-050}

Até o final do primeiro semestre de 2015, no âmbito do Estado de Minas Gerais, existiam nove contratos de Parcerias Público-Privadas vigentes, dentre os quais a PPP Rodovia MG-050. A PPP Rodovia MG-050 teve seu contrato de Concessão Patrocinada assinado em 21 de maio de 2007 entre a Secretaria de Estado de Transporte e Obras Públicas (SETOP) e a Concessionária AB Nascentes das Gerais, tendo como intervenientes o Departamento de Estradas de Rodagem (DER/MG) e a Companhia de Desenvolvimento Econômico de Minas Gerais (CODEMIG), conforme licitação por concorrência realizada em 07 de agosto de 2006, homologada em 09 de maio de 2007. Esse é o primeiro contrato de PPP do país na área de infraestrutura rodoviária e, em decorrência desse fato, já acumula volume de dados históricos razoável para subsidiar a análise aqui proposta.

O contrato da PPP Rodovia MG-050 prevê a recuperação, ampliação e manutenção da rodovia até 2032. Essa rodovia conta com uma extensão de 372 km, interligando a região metropolitana de Belo Horizonte à divisa dos Estados de Minas Gerais e São Paulo, prevendo a realização de investimentos na ordem de $R \$ 650$ milhões.

O contrato da PPP Rodovia MG-050 configura a modalidade de PPP denominada patrocinada por prever a possibilidade de complementação, pelo agente privado, da contraprestação pecuniária paga pelo Poder Público com arrecadação de tarifas pagas pelos usuários que trafegam sobre a rodovia.

Assim, no momento do processo licitatório para seleção do parceiro privado, os licitantes apresentaram um valor proposto para a contraprestação pecuniária considerando, de um lado, todos os desembolsos programados relativos às obras de recuperação, manutenção, ampliação, melhoria e conservação especial para o atendimento às condições operacionais mínimas da rodovia indicadas em contrato e, do outro lado, a receita de pedágio projetada, conforme projeção do volume de tráfego e tarifa básica, ambos também previstos em contrato.

Dessa forma, constata-se que a projeção do volume de tráfego sobre a rodovia é dado fundamental para toda a concepção dessa concessão, sendo potenciais diferenças entre o tráfego efetivamente observado e o tráfego projetado um risco operacional intrínseco ao projeto. 
A Cláusula 30 do contrato da PPP Rodovia MG-050 dispõe sobre o compartilhamento do risco de variação do volume de tráfego na rodovia, o qual é representado pela possibilidade de divergências apuradas a cada período de 12 meses entre 0 tráfego projetado e o tráfego efetivamente observado naquele período. Tal risco é compartilhado entre as partes na proporção de 50\% para a Concessionária e $50 \%$ para a o Poder Público. Destaca-se, porém, a existência de previsão contratual que estabelece uma margem de variação das projeções, considerando que diferenças de até $10 \%$, para mais ou para menos, dos volumes de tráfego originalmente projetados são de risco exclusivo da Concessionária do projeto, não implicando, portanto, em ônus financeiros para o Poder Público.

Afora essa circunstância, o risco de variação da demanda pelo serviço rodoviário é compartilhado igualmente entre as partes. Em casos de variação do volume de tráfego para além do projetado para o período, a receita adicional obtida com a tarifa de pedágio paga pelo excedente de veículos que circulam sobre a rodovia é compartilhada entre o parceiro privado e o Poder Público, na proporção de $50 \%$ para cada. Por outro lado, caso seja observada variação do volume de tráfego para aquém do projetado para o período, $50 \%$ da queda da receita tarifária projetada deve ser compensada pelo Poder Concedente, em favor do parceiro privado.

O risco de demanda por um dado serviço, por vezes denominado também como risco de mercado, pode ser motivado por mudanças na atividade econômica, surgimento de serviços alternativos ou ainda por mudanças no perfil sócio demográfico da população beneficiária daquele serviço (Victoria, 2001). Tal risco refere-se à possibilidade de variação do volume de usuários do bem ou serviço concedido em relação àquele projetado no momento de elaboração do contrato de PPP (Martins \& Andrade, 2016). Em contratos de PPP o risco de demanda deve ser tratado com atenção, sendo quase sempre recomendável compartilhar a responsabilidade sobre ele, uma vez que esse é gerenciável de maneira limitada por ambas as partes (Valila, 2005).

Dessa forma, para o desenvolvimento da análise aqui proposta, elege-se 0 volume de tráfego como variável-chave desta PPP, considerando, portanto, que o controle e acompanhamento dessa variável já mitiga grande parte do risco fiscal assumido pelo Estado em relação a esse contrato. 


\section{Metodologia}

Para o desenvolvimento da investigação aqui proposta, busca-se desenvolver uma análise comparativa do comportamento efetivo do tráfego observado sobre a rodovia MG-050 em relação à projeção apresentada à ocasião da assinatura do contrato de Parceria, visando ponderar se existe a tendência de ocorrência de volume de tráfego inferior àquele projetado, o que acarretaria na assunção de maior dispêndio por parte do Poder Público, em decorrência do compartilhamento desse risco com a Concessionária.

Dessa forma, são utilizados registros históricos do volume de tráfego referentes ao período de 2008 a 2015, para proceder à comparação entre o volume de tráfego projetado e o observado. A fim de identificar a tendência da curva do volume de tráfego, realiza-se ainda processo de reamostragem, a partir do método estatístico bootstrap, conforme será exposto a seguir.

O Anexo XV do contrato da PPP Rodovia MG-50 traz informações sobre a projeção de tráfego elaborada pelo DER/MG para todo o prazo da concessão, no qual o tráfego é dado pelo somatório do volume de automóveis e caminhões, convertidos em número de eixos, discriminados por praça de pedágio e por ano. A metodologia adotada pelo DER/MG para elaborar tal projeção não está explícita nos documentos contratuais, o que é tido como uma limitação para o gerenciamento do risco de oscilação do volume de tráfego. Contudo, sabe-se que os valores expressos no referido anexo foram elaborados tendo em vista uma margem de fuga e impedância para cada praça de pedágio contemplada pelo projeto.

Para a análise comparativa do comportamento efetivo do tráfego em relação à projeção apresentada à ocasião da assinatura do contrato, com o intuito de identificar se há tendência de convergência ou divergência entre eles, foram utilizados como fontes dos registros históricos os dados mensais elaborados e divulgados pela SETOP, por meio dos Relatórios Executivos da MG-050 (Recuperado em 01, jul, 2015 de http://transportes.mg.gov.br/component/gmg/page/1409-relatorio-executivo).

Destaca-se que os Relatórios Executivos não apresentam os dados do tráfego efetivo observados durante o primeiro ano da concessão. 
A partir dessas fontes de dados, elaborou-se a Tabela 1, compilando as informações referentes ao tráfego mensal efetivamente observado sobre a rodovia, a partir do segundo ano de concessão, quando entraram em operação as praças de pedágio, até o final do primeiro semestre de 2015.

Para a realização do procedimento de reamostragem a que se propõe essa pesquisa, quanto maior a base de dados de entrada, mais precisos os dados simulados. De acordo com Pillar (2004), quanto maior o número de unidades amostrais, maior a probabilidade de que as estimativas dos parâmetros obtidas a partir das amostras revelem o estado verdadeiro dos parâmetros no universo amostral.

Nesse sentido, entendeu-se ser mais conveniente trabalhar com os dados mensais contidos nos Relatórios Executivos da MG-050, em detrimento dos dados consolidados em base anual. Tal escolha justifica-se pelo fato de que a projeção de tráfego contida no Anexo XV do contrato de PPP em análise apresenta o volume de tráfego projetado por ano, enquanto os registros do tráfego efetivamente observado na rodovia contêm tal dado discriminado por mês. Dessa forma, de modo a aproveitar a base de dados de entrada mais ampla disponível, divulgada mensalmente e, ainda assim, compatibilizar a análise comparativa com a projeção referencial, dada para cada ano da concessão, utilizaram-se os dados mensais acumulados, ou seja, considerou-se cada registro mensal contido nos Relatórios Executivos acrescido dos registros dos últimos onze meses. Por esse motivo, a análise proposta foi feita a partir do ano 3 da concessão, uma vez que os dados do ano 2 foram utilizados para o cálculo do tráfego acumulado do ano subsequente.

De modo geral, o início da execução de uma concessão é considerado a partir da data de assinatura de seu respectivo contrato, salvo quando esse dispõe, expressamente, de modo diverso. No caso da PPP Rodovia MG-050, o início da execução da concessão é considerado a partir da data de efetiva transferência do gerenciamento do sistema rodoviário do Poder Público para o parceiro privado, a qual ocorreu em 13 de junho de 2007. Dessa forma, o prazo de concessão, de 25 anos, é contado a partir dessa data (Franco, 2007). Assim, cada ano de concessão é contabilizado de "jun", correspondente a 13 de junho do ano anterior, até "jun"”, correspondente a 12 de junho do ano seguinte.

A partir desses dados, realizou-se processo de reamostragem pelo método bootstrap, a fim de gerar outros potenciais valores para o tráfego sobre a rodovia 
MG-050 no período do ano 3 ao ano 8 da concessão, permitindo identificar intervalo de confiança para os valores médios calculados a partir dos dados simulados.

O bootstrap é um método que permite simulações estatísticas com base em dados amostrais existentes (Lavoranti, 2003). Esse método se distingue de outros métodos de reamostragem pelo fato de que possibilita a obtenção da distribuição empírica da amostra estimada, não exigindo conhecimento prévio da distribuição da população analisada (Hall \& Horowitz, 2013).

A aplicação do bootstrap consiste na realização de reamostragem com reposição de tamanho $n$ da amostra original (Ramos \& Ferreira, 2009). Assim, segundo os autores, retira-se uma amostra de tamanho $n$ da população e realiza-se a reamostragem com reposição, obtendo uma nova amostra de tamanho $n$ da amostra original. Ainda segundo os mesmos autores, esse procedimento é executado repetidas vezes, obtendo-se, assim, as estimativas que serão usadas para gerar a distribuição denominada distribuição bootstrap.

Para análise dos potenciais valores de tráfego anual, foi replicado o processo de reamostragem para cada ano de análise, gerando 1000 (mil) simulações referentes a cada ano, considerando amostras de dimensões idênticas às amostras originais, ou seja, 13 (treze) dados por período.

\section{Tabela 1}

Tráfego mensal efetivamente observado na Rodovia MG-050

\begin{tabular}{|c|c|c|c|c|}
\hline ANO & \# & MÊS & $\begin{array}{c}\text { TRÁFEGO } \\
\text { OBSERVA } \\
\text { DO }\end{array}$ & $\begin{array}{c}\text { ACUMULAD } \\
0\end{array}$ \\
\hline \multirow{13}{*}{$\begin{array}{c}2007 / \\
2008\end{array}$} & \multirow{13}{*}{1} & jun $^{1}$ & & \\
\hline & & jul & & \\
\hline & & ago & & \\
\hline & & set & & \\
\hline & & out & & \\
\hline & & nov & & \\
\hline & & $\mathrm{dez}$ & & \\
\hline & & jan & & \\
\hline & & fev & & \\
\hline & & mar & & \\
\hline & & $\overline{a b r}$ & & \\
\hline & & mai & & \\
\hline & & jun ${ }^{2}$ & & \\
\hline \multirow{5}{*}{$\begin{array}{c}2008 / \\
2009\end{array}$} & \multirow{5}{*}{2} & jun $^{1}$ & 921.047 & \\
\hline & & jul & 1.640 .322 & \\
\hline & & ago & 1.512 .433 & \\
\hline & & set & 1.512 .257 & \\
\hline & & out & 1.534 .473 & \\
\hline
\end{tabular}

\begin{tabular}{|c|c|c|c|c|}
\hline ANO & \# & MÊS & $\begin{array}{c}\text { TRÁFEGO } \\
\text { OBSERVA } \\
\text { DO }\end{array}$ & $\begin{array}{c}\text { ACUMULAD } \\
0\end{array}$ \\
\hline \multirow{13}{*}{$\begin{array}{c}2010 / 20 \\
11\end{array}$} & \multirow{13}{*}{4} & jun 1 & 911.827 & 17.088 .205 \\
\hline & & jul & 1.694 .687 & 17.269 .196 \\
\hline & & ago & 1.722 .634 & 17.458 .832 \\
\hline & & set & 1.711 .948 & 17.538 .527 \\
\hline & & out & 1.718 .749 & 17.738 .858 \\
\hline & & nov & 1.634 .463 & 17.798 .619 \\
\hline & & dez & 1.723 .870 & 18.000 .855 \\
\hline & & jan & 1.582 .502 & 18.149 .845 \\
\hline & & fev & 1.492 .724 & 18.049 .364 \\
\hline & & mar & 1.610 .780 & 18.091 .776 \\
\hline & & $\mathrm{abr}$ & 1.650 .055 & 18.121 .345 \\
\hline & & mai & 1.729 .276 & 19.183 .512 \\
\hline & & $\mathrm{jun}^{2}$ & 655.831 & 18.927 .516 \\
\hline \multirow{5}{*}{$\begin{array}{l}2011 / \\
2012\end{array}$} & \multirow{5}{*}{5} & jun ${ }^{1}$ & 1.013 .191 & 18.246 .020 \\
\hline & & jul & 1.769 .408 & 18.292 .794 \\
\hline & & ago & 1.819 .982 & 18.400 .828 \\
\hline & & set & 1.784 .103 & 18.466 .182 \\
\hline & & out & 1.717 .054 & 18.548 .774 \\
\hline
\end{tabular}




\begin{tabular}{|c|c|c|c|c|}
\hline & & nov & 1.354 .295 & \\
\hline & & dez & 1.373 .364 & \\
\hline & & jan & 1.328 .979 & \\
\hline & & fev & 1.250 .847 & \\
\hline & & mar & 1.410 .716 & \\
\hline & & $a b r$ & 1.431 .506 & \\
\hline & & mai & 1.491 .883 & \\
\hline & & jun² & 582.482 & \\
\hline \multirow{13}{*}{$\begin{array}{l}2009 / \\
2010\end{array}$} & \multirow{13}{*}{3} & jun 1 & 862.344 & 15.645 .578 \\
\hline & & jul & 1.624 .546 & 15.757 .690 \\
\hline & & ago & 1.513 .696 & 15.759 .129 \\
\hline & & set & 1.532 .998 & 15.757 .654 \\
\hline & & out & 1.632 .253 & 16.035 .612 \\
\hline & & nov & 1.518 .419 & 16.180 .667 \\
\hline & & dez & 1.574 .701 & 16.426 .389 \\
\hline & & jan & 1.521 .634 & 16.697 .176 \\
\hline & & fev & 1.433 .511 & 16.719 .971 \\
\hline & & mar & 1.593 .205 & 16.881 .670 \\
\hline & & $a b r$ & 1.568 .368 & 16.958 .155 \\
\hline & & mai & 1.620 .486 & 17.996 .159 \\
\hline & & jun ${ }^{2}$ & 667.109 & 17.800 .923 \\
\hline
\end{tabular}

\begin{tabular}{|c|c|c|c|c|}
\hline & nov & 1.643 .763 & 18.468 .667 \\
\hline & & $\mathrm{dez}$ & 1.685 .304 & 18.571 .470 \\
\hline & & jan & 1.616 .363 & 18.695 .109 \\
\hline & & fev & 1.583 .128 & 18.667 .457 \\
\hline & & mar & 1.675 .945 & 18.693 .348 \\
\hline & & $\mathrm{abr}$ & 1.660 .957 & 18.625 .029 \\
\hline & & mai & 1.682 .657 & 19.651 .855 \\
\hline & & jun $^{2}$ & 614.206 & 19.252 .870 \\
\hline \multirow{13}{*}{$\begin{array}{l}2012 / \\
2013\end{array}$} & \multirow{13}{*}{6} & jun ${ }^{1}$ & 968.309 & 18.451 .771 \\
\hline & & jul & 1.755 .354 & 18.387 .143 \\
\hline & & ago & 1.806 .485 & 18.409 .525 \\
\hline & & set & 1.723 .776 & 18.416 .247 \\
\hline & & out & 1.826 .421 & 18.598 .905 \\
\hline & & nov & 1.742 .202 & 18.655 .803 \\
\hline & & $\mathrm{dez}$ & 1.713 .010 & 18.752 .450 \\
\hline & & jan & 1.682 .506 & 18.851 .828 \\
\hline & & fev & $\begin{array}{l}1.516 .712 \\
\end{array}$ & 18.692 .595 \\
\hline & & $\mathrm{mar}$ & 1.742 .774 & 18.774 .412 \\
\hline & & $\mathrm{abr}$ & 1.698 .390 & 18.790 .145 \\
\hline & & mai & 1.765 .134 & 19.941 .073 \\
\hline & & $\mathrm{jun}^{2}$ & 706.054 & 19.678 .817 \\
\hline
\end{tabular}

Continua

\begin{tabular}{|c|c|c|c|c|c|c|c|c|c|}
\hline & & & & & & & & & Continuação \\
\hline ANO & \# & MÊS & $\begin{array}{c}\text { TRÁFEGO } \\
\text { OBSERVA } \\
\text { DO }\end{array}$ & $\begin{array}{c}\text { ACUMULAD } \\
0\end{array}$ & ANO & \# & MÊS & $\begin{array}{c}\text { TRÁFEGO } \\
\text { OBSERVA } \\
\text { DO }\end{array}$ & $\begin{array}{c}\text { ACUMULAD } \\
0\end{array}$ \\
\hline & & jun $^{1}$ & 986.87 & 18.910 .334 & & & jun 1 & 841 & 19.502 .000 \\
\hline & & jul & 1.859 .000 & 18.962 .849 & & & Jul & 1.771 .000 & 19.399 .000 \\
\hline & & ago & 1.874 .000 & 19.113 .073 & & & ago & 1.850 .000 & 19.454 .000 \\
\hline & & set & 1.795 .000 & 19.081 .652 & & & Set & 1.845 .000 & 19.417 .000 \\
\hline & & out & 1.882 .000 & 19.221 .450 & & & out & 1.904 .000 & 19.542 .000 \\
\hline & & nov & 1.779 .000 & 19.287 .440 & & & nov & 1.719 .000 & 19.498 .000 \\
\hline $2013 /$ & 7 & dez & 1.763 .000 & 19.367 .934 & D14/20 & 8 & dez & 1.816 .000 & 19.515 .000 \\
\hline & & jan & 1.799 .000 & 19.650 .222 & & & jan & 1.763 .000 & 19.644 .000 \\
\hline & & fev & 1.634 .000 & 19.541 .448 & & & fev & 1.499 .000 & 19.426 .000 \\
\hline & & mar & 1.717 .000 & 19.560 .058 & & & mar & 1.692 .000 & 19.341 .000 \\
\hline & & $a b r$ & 1.777 .000 & 19.571 .924 & & & $a b r$ & 1.672 .000 & 19.213 .000 \\
\hline & & mai & 1.800 .000 & 20.665 .870 & & & mai & 1.860 .000 & 20.232 .000 \\
\hline & & $\mathrm{jun}^{2}$ & 841 & 20.520 .000 & & & jun ${ }^{2}$ & 1.737 .000 & 21.128 .000 \\
\hline
\end{tabular}

Fonte: Elaborado pelos autores com dados da pesquisa

Para estimar o intervalo de confiança das médias, utilizou-se o método do percentil. Esse método consiste na identificação da distribuição e, posteriormente, cálculo dos percentis da distribuição, determinando assim os limites inferiores e superiores do intervalo de confiança (Efron \& Tibshirani, 1993). Para tal, considerouse $\alpha=0,05(5 \%)$. 


\section{Apresentação e Discussão dos Resultados}

A partir de estatísticas descritivas aplicadas sobre as amostras compostas pelos dados mensais acumulados foi possível determinar o volume médio de tráfego observado até meados de 2015, ocasião de fechamento dessa pesquisa. As estatísticas descritivas foram aplicadas também sobre as amostras geradas por meio do processo de simulação, sendo que, para essas, determinou-se o intervalo de confiança para os valores médios apresentados, considerando-se $\alpha=0,05$.

\section{Tabela 2}

Dados tráfego anual gerados a partir das simulações bootstrap

\begin{tabular}{|c|c|c|c|c|}
\hline ANO & ANO & $\begin{array}{c}\text { MÉDIA DADOS } \\
\text { HISTÓRICOS }\end{array}$ & $\begin{array}{c}\text { MÉDIA DAS } \\
\text { SIMULAÇÕES }\end{array}$ & $\begin{array}{c}\text { INTERVALO DE CONFIANÇA } \\
\text { PARA MÉDIA DAS } \\
\text { SIMULAÇÕES }\end{array}$ \\
\hline $2007 / 2008$ & 1 & & & \\
\hline $2008 / 2009$ & 2 & & & 15.759 .129 a 16.881 .670 \\
\hline $2009 / 2010$ & 3 & 16.510 .000 & 16.400 .000 & 17.538 .527 a 18.121 .345 \\
\hline $2010 / 2011$ & 4 & 17.960 .000 & 17.930 .000 & 18.466 .182 a 18.693 .348 \\
\hline $2011 / 2012$ & 5 & 18.660 .000 & 18.570 .000 & 18.451 .771 a 18.790 .145 \\
\hline $2012 / 2013$ & 6 & 18.800 .000 & 18.690 .000 & 19.113 .073 a 19.571 .924 \\
\hline $2013 / 2014$ & 7 & 19.500 .000 & 19.380 .000 & 19.417 .000 a 19.542 .000 \\
\hline $2014 / 2015$ & 8 & 19.640 .000 & 19.480 .000 & \\
\hline
\end{tabular}

Fonte: Elaborado pelos autores com dados da pesquisa.

Para proceder à discussão do risco fiscal assumido pelo Poder Público em razão do compartilhamento do risco de variação do volume de tráfego nessa PPP, faz-se necessário confrontar os valores projetados pelo estudo de tráfego do DER/MG, considerando a margem de variação de $10 \%$ para mais ou para menos, com os valores acima apresentados. Para tanto, foram considerados os valores de projeção divulgados também nos Relatórios Executivos, pois esses apresentam pequenas divergências em relação aos valores expressos no termo contratual, o que se acredita ser motivado pelo fato de que foi aplicada uma metodologia para compatibilização dos dados do contrato com os dados apurados na execução.

\section{Tabela 3}

Dados da projeção de tráfego anual elaborada pelo DER/MG, considerada a margem de variação de $10 \%$ para mais ou para menos

\begin{tabular}{c|c|c|c|c}
\hline ANO & ANO & $\begin{array}{c}\text { PROJEÇÃO } \\
\text { DER/MG }\end{array}$ & $+\mathbf{+ 1 0 \%}$ & $\mathbf{- 1 0 \%}$ \\
\hline $2007 / 2008$ & 1 & & & \\
\hline $2008 / 2009$ & 2 & & & $17.131 .500,00$ \\
\hline $2009 / 2010$ & 3 & $19.035 .997,26$ & $20.938 .500,00$ & \\
\hline
\end{tabular}




\begin{tabular}{l|l|l|l|l}
\hline $2010 / 2011$ & 4 & $19.507 .569,86$ & $21.457 .700,00$ & $17.556 .300,00$ \\
\hline $2011 / 2012$ & 5 & $20.015 .977,48$ & $22.017 .575,23$ & $18.014 .379,73$ \\
\hline $2012 / 2013$ & 6 & $20.438 .754,02$ & $22.482 .629,42$ & $18.394 .878,62$ \\
\hline $2013 / 2014$ & 7 & $20.961 .501,37$ & $23.057 .651,51$ & $18.865 .351,23$ \\
\hline $2014 / 1015$ & 8 & $21.459 .734,25$ & $23.605 .707,68$ & $19.313 .760,83$ \\
\hline
\end{tabular}

Fonte: Elaborado pelos autores com dados da pesquisa.

A Figura 1 permite a análise do risco de variação do volume de tráfego na PPP Rodovia MG-050 a partir da comparação entre os dados projetados pelo DER/MG considerando a margem de variação contratualmente estabelecida como risco exclusivo do parceiro privado - com os dados históricos efetivamente observados no período e, ainda, com os dados simulados a partir da análise aqui proposta.

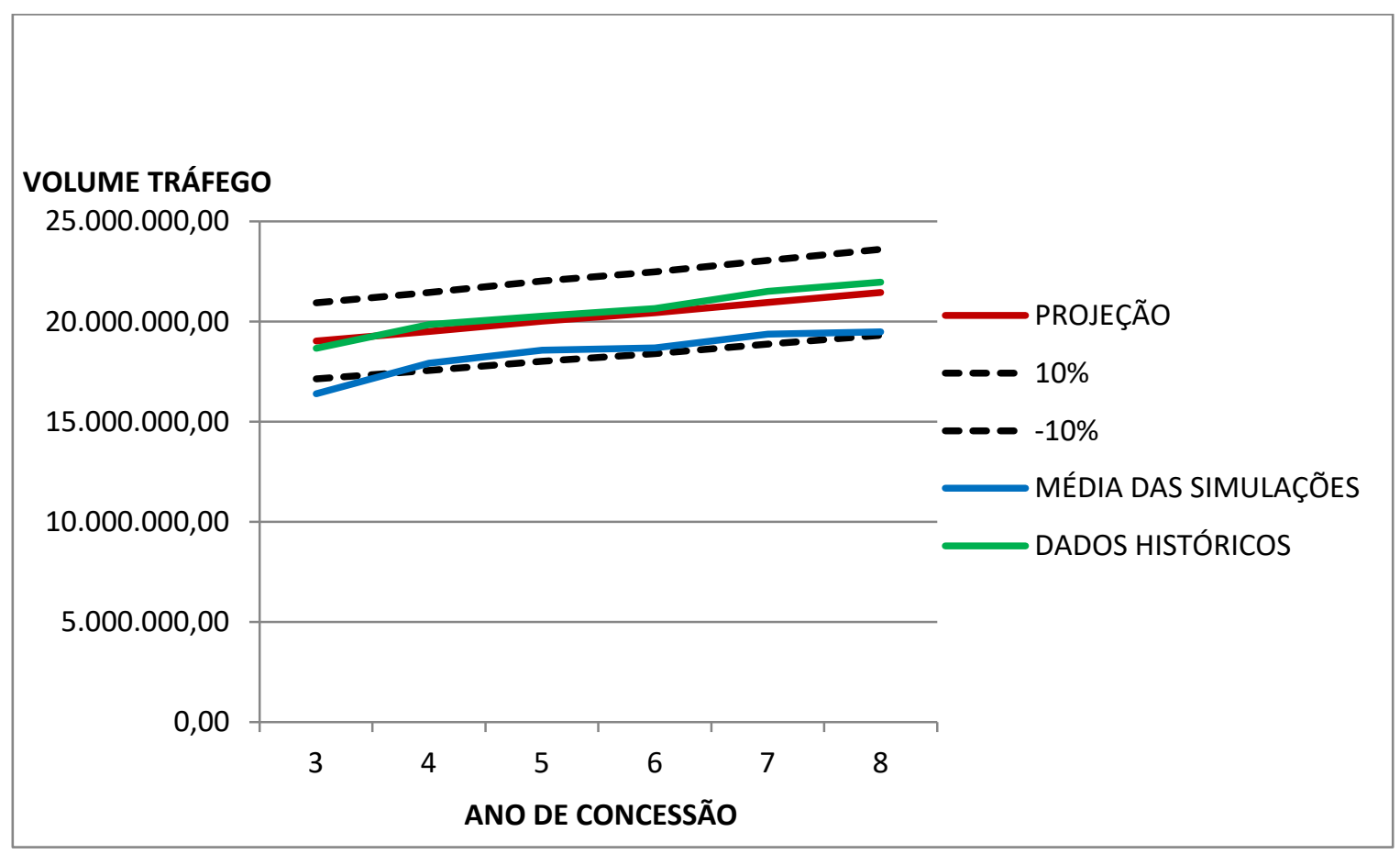

\section{Figura 1}

Análise de Risco de Tráfego na Rodovia MG-050

Fonte: Elaborado pelos autores com dados da pesquisa.

\section{Considerações Finais}

Dado o exposto, percebe-se que, no período analisado, o volume de tráfego efetivamente observado foi bem próximo ao volume projetado. Isso quer dizer que o Governo do Estado de Minas Gerais não teve, até o presente momento, gastos adicionais, tampouco ganhos econômicos advindos do compartilhamento do risco de demanda com o parceiro privado nesse contrato de concessão. No que se refere às simulações geradas a partir dos dados históricos observados, as quais refletem a 
tendência de oscilação do volume de tráfego em relação àquele projetado, nota-se que essas se mantêm muito próximas da margem inferior de variação da projeção, porém, na maior parte do período analisado, ainda dentro do intervalo estabelecido como de risco exclusivo do parceiro privado.

Pode-se afirmar, portanto, que o estudo de tráfego que subsidiou a elaboração da projeção de tráfego pelo DER/MG, bem como o estabelecimento da amplitude da margem de variação do mesmo, parece ter sido bem elaborado e que tais dados representam bem a realidade observada ao longo da execução do contrato até o momento atual. Ressalta-se, porém, que a ausência de divulgação das premissas consideradas para a construção da projeção limita a realização de uma análise pormenorizada da consistência da mesma.

Conclui-se que a tarefa de determinação das premissas contratuais é de suma importância para o controle do risco fiscal a ser assumido pelo Poder Público em cada nova PPP. Conhecer bem a realidade da operação do objeto contratual é fundamental para a determinação precisa das cláusulas de compartilhamento de riscos e responsabilidades entre as partes, de modo que, ao mesmo tempo, tenhase um projeto financeiramente sustentável para o parceiro privado e também orçamentariamente viável para o poder público, sem que haja oneração excessiva de nenhum dos dois lados.

Sugere-se que trabalhos futuros repliquem a metodologia utilizada na presente pesquisa para a análise do risco fiscal assumido pelo Poder Público em outros contratos de PPP, a fim de evidenciar potenciais passivos contingentes tomados pelos entes federados nesses projetos.

\section{Referências}

Archanjo, P. F. (2006). A Regulamentação das Parcerias Público-Privadas (PPP) no Brasil e a Experiência do Reino Unido. (Dissertação Mestrado em Economia.

PUC, São Paulo, SP, Brasil).

Belsito, B. G., \& Viana, F. B. (2013). O limite de comprometimento da Receita Corrente Líquida em contratos de Parceria Público-Privada. Revista do BNDES, 39. 
Campos, C. A. (2015). Uma discussão sobre o tratamento contábil dos riscos dos contratos de concessão do governo brasileiro. (Trabalho de conclusão de curso. Bacharelado em Ciências Contábeis, Universidade de Brasília, Brasília, DF, Brasil).

Cunha, A. (2005). Disciplina fiscal e qualidade do gasto público: fundamentos da reforma orçamentária (v. 3). FGV Editora.

Efron, B., \& Tibshirani, R. J. (1993). An introduction to the bootstrap Chapman \& Hall. New York: Springer-Science+Businessmédia, B. V.

Franco, G. V. (2007). Parcerias Público-Privadas no Brasil: em busca de eficiência por meio da alocação de riscos. (Dissertação Mestrado em Economia Política. Pontifícia Universidade Católica de São Paulo, São Paulo, SP, Brasil).

Fundo Monetário Internacional. Manual de transparência fiscal. FMI, 2007. Recuperado de <https://www.imf.org/external/np/fad/trans/por/manualp.pdf>.

Guimarães, F. V. (2010). A responsabilidade fiscal na Parceria Público-Privada. Revista Eletrônica de Direito Administrativo Econômico, 20.

Hall, P., \& Horowitz, J. (2013). A simple bootstrap method for constructing nonparametric confidence bands for functions. Ann. Statist. 41(4), 18921921. doi:10.1214/13-AOS1137. http://projecteuclid.org/euclid.aos/1378386242.

Lavoranti, O. J. (2003). Estabilidade e adaptabilidade fenotípica através da reamostragem "bootstrap" no modelo AMMI. (Tese de Doutorado. Universidade de São Paulo, São Paulo, SP, Brasil).

Lei Complementar n. 101, de 04 de maio de 2000. (2000). Estabelece normas de finanças públicas voltadas para a responsabilidade na gestão fiscal e dá outras providências. Diário Oficial da União. Brasília, DF: Exército Brasileiro.

Lei n. 11.079, de 30 de dezembro de 2004. (2004). Institui normas gerais para licitação e contratação de parceria público-privada no âmbito da administração pública. Diário Oficial da União. Brasília, DF: Exército Brasileiro.

Loiola, F.A.A. (2013). The formulation of Public-Private Partnership projects for infrastructure development in Brazil: An institutional analysis of the Municipality of Fortaleza. (Tese de Doutorado, University of Sheffield).

Martins, V. A., \& Andrade, M. E. M. C. (2016). A Regulação Contábil dos Contratos de Parcerias Público-Privada-PPP, como instrumento de transparência das entidades públicas e privadas. Revista Controle (Online), 7(1), 235-256.

Nishizawa, T. (2011). Changes in Development Finance in Asia: Trends, Challenges, and Policy Implications. Asian Economic Policy Review, 6(2), 225-244.

Pillar, V. D. (2004). Suficiência amostral. Amostragem em Limnologia. Rima, São Carlos, 25-43. 
Ramos, P. S., \& Ferreira, D. F. (2009). Agrupamento de médias via bootstrap de populações normais e não-normais, Revista Ceres, 56, 140-149.

Rocha, C. A. A. (2010). O controle das Parcerias Público-Privadas. In F. B. Meneguin. (Org.). Agenda Legislativa para o Desenvolvimento Nacional. Brasília: Senado Federal, pp. 185-198.

Rodrigues, V. P., \& Lopes, F. A. (2006). Anexo de Riscos Fiscais: características do instrumento e sua importância para a evidenciação das contas públicas. Monografia (Especialização em Contabilidade e Orçamento Público). Universidade de Brasília, Brasília, DF. Brasil.

Sarmento, J. M., \& Renneboog, L. (2014). Public-Private Partnerships: Risk Allocation and Value for Money. Center Discussion Paper, v. 2014-022, Tilburg University.

Thamer, R., \& Lazzarini, S. G. (2015). Projetos de parceria público-privada: fatores que influenciam o avanço dessas iniciativas. Revista de Administração Pública, 49(4), 819-846.

Valila, T. (2005). How expensive are cost savings? On the economics of publicprivate partnerships. European Investment Bank Papers, 10, 95-116.

Victoria (2001). Risk allocation and contractual issues. Department of Treasury and Finance. State of Victoria, Australia. 